\title{
A Theory of Construction Management?
}

\author{
Gerard de Valence, (University Technology of Sydney, Australia)
}

\section{Theory}

The links between construction management $(\mathrm{CM})$, and for that matter construction economics (CE) and theory, are not strong (see de Valence 2011). This may be one of the reasons why they have not gained complete acceptance as academic disciplines and are not seen as distinct branches of management and economics respectively. Another reason may be that products and production (the focus of management and economic theories respectively) are not the same as projects and project management in general, and construction projects and CM in particular.

So, are management theories of production product-based or process-based? The emphasis seems to be mainly on the range of methods and techniques available to improve the efficiency with which products are delivered, although many of these products are management decisions or plans. Processes are secondary, because they are bundled with the production decision, and despite the appearance of diversity in the range of management theories, the approach taken typically treats the firm as a 'black box' that turns inputs into outputs using a range of capabilities (Porter 1980). These then are a productbased set of theories.

There are a number of economic concepts involved in production theory. The important ones include returns to scale, price elasticity of demand, elasticity of substitution between input factors, and technological change. Technological change has the three aspects of rate of technical change, acceleration of technical change over time, and the rate of change of marginal products (of factors). These economic effects come from the underlying production process, or processes, that firms choose between when making production decisions. The economic theory of production focuses on the input demand and output supply functions under a technical constraint that describes a range of production processes available to a firm.

In that case, could production theory be relevant to $\mathrm{CM}$, because the delivery of a new building or construction project is clearly about producing something. A relationship between $\mathrm{CM}$ and the economic theory of production is plausible because both are concerned with technology choices. However, production theory is complex. The economic theory of production developed out of the classical concern with marginal productivities into a production function focused on substitutability of factors under a technological constraint. Can CM be reinterpreted in these terms? Would that improve industry performance? Can a theory be founded on the characteristics of the industry?

A new book from Milan Radosavljevic and John Bennett takes on these questions. Construction Management Strategies: A theory of construction management (2012) attempts to provide that foundation by proposing a theory of construction management which identifies the actions which help construction projects and companies to be efficient. It takes on the challenge of creating a precise, tightly defined model of construction management (CM), using five clearly differentiated methods for the delivery of building and construction projects. It is an ambitious and intellectually bold attempt to introduce new thinking into the field. 
What they don't do is draw on any of the many theories of management or production available. On one hand this seems to be an extreme case of exceptionalism - that construction is different from all other industries - school of thought. In their defence, on the other hand, Radosavljevic and Bennett argue that construction is different, because it is complex:

projects have a number of interacting teams where outcomes in the future depend on the number of involved teams, the quality of relationships between interacting teams and their performance variability. In addition there is also unpredictable interference which may arise from numerous external factors (p. 77).

\section{A Theory of $\mathrm{CM}$}

The authors aim is to provide a "rigorous theory" based on a "tool kit of concepts and relationships" that will improve the efficiency and quality of "construction products". The distinction between the conventional approach of CM, where contractors deliver projects, and the idea of companies producing a product is an important element in the thinking behind the theory proposed here. A related aim of the book is therefore to raise the viewpoint of $\mathrm{CM}$ from projects to the companies that manage projects.

Following that intention they "identifies and defines the concepts needed to understand CM". Radosavljevic and Bennett somewhat self-consciously develop their theory without drawing on general management theories, rather wanting to base their ideas on construction industry projects and practice, which makes these definitions extremely important to their theory of $\mathrm{CM}$ and to our understanding of that theory. The concepts are construction products and processes, organizations, interactions and relationships, and learning and performance. The main factors are communication, feedback lops, and how well established relationships are (called internal) or not (called boundary relationships). The definition of $\mathrm{CM}$ is "taking responsibility for the performance of a construction organization", measured by efficiency, which is "inversely related to the waste caused by complexity and external interference which prevent organizations achieving their agreed objectives".

These concepts and definitions are important in the exploration of the theory of $\mathrm{CM}$ which is the core of the book. Through a series of propositions about CM, CM teams (task groups) and related efficiency conditions they build a detailed description of construction organizations, processes and management. This results in "the basic concepts used in the theory of $\mathrm{CM}$ in mathematical terms to provide effective measures of features of construction which have a crucial impact on CM decisions". These are the six inherent difficulty indicators" (IDIs), which are the fundamental variables in the theory of CM and are used to determine the most appropriate CM strategy. These IDIs are:

1. Established relationships - consequential relationships between interacting teams that existed before the project started;

2. Relationship fluctuation - differences between times during the project with and without established relationships between teams;

3. Relationship quality - time teams have spent previously working together;

4. Relationship configuration - the pattern of team interactions over the project (this is a quite complex indicator because it can vary greatly over time, i.e. during a project);

5. Performance variability - team performance may not be consistent between projects;

6. External interference - factors outside the control of the project managers.

Project size is measured in the number of team days, because " $\mathrm{CM}$ is concerned with the selection and organization of teams". This results in a set of five size groups, from minor (100 team days) to normal (5,000 team days) to mega (25,000 team days). The theory then guides the choice of CM strategy for a project and the IDIs can check the effect of selecting a particular strategy for that project. Here CM strategy is the approach used to deliver the project, and the five "major CM approaches currently used in practice" are:

de Valence G (2012) 'A theory of construction management?', Australasian Journal of Construction Economics and Building, 12 (3) 95-100 
1. Traditional construction - includes the UK's "developed traditional construction" or architect led version, and the US (specialist contractor design) and European (architect and engineers design) versions;

2. Design build - a single point of responsibility for delivery of the project;

3. Management approaches- design and management teams working under the general direction of the client;

4. Partnering - concentrates on establishing effective relationships rather than roles and responsibilities, and can be a strategic or ongoing relationship;

5. Total construction service - industrialised building modelled on car manufacturers with an emphasis on reliability, quality and continuous improvement.

Those familiar with John Bennett's work over the last couple of decades will not be surprised that the Japanese construction industry features in the discussion of total construction service. The Big Five contractors and the industrialised home builders are held up as prime examples of what total service is and how it is delivered. To illustrate the theory they use an interesting case study of a large, family-run German building company. They clearly believe this is the future of the industry, and their theory not surprisingly supports that view.

Each of the CM approaches is described and discussed in some detail, and a hypothetical project is analysed to quantify the six IDIs, and from these values get a forecast (prediction?) of the project's likelihood of successful completion. These discussions demonstrate the application of the theory and the use of the IDIs. Whether all this is a theory in the scientific sense of predictive value can be argued about. If data were gathered on a number of projects, and as the sample increases, the ability of the models six variables (the IDIs) to predict the "probability of project completion as planned" will become apparent.

\title{
The Theory of Lean Construction
}

This use of a theory of $\mathrm{CM}$ as a series of interactions between teams under internal and external constraints is, as far as I know, a completely new and novel approach to CM, Indeed, outside the lean construction (LC) movement there has been limited interest in a, or any, theory of production as applied to the construction industry. That said, LC can be also be thought of as a philosophy, as can be seen in many of the publications by the founder of LC, Lauri Koskela (his Editorial in a 2008 Special Issue of Building Research and Information on theories of the built environment, that did not include $\mathrm{CM}$, is a good example).

In the evolution of Koskela's ideas since the 1992 publication of "Application of the New Production Philosophy to Construction" production theory has developed into what is now the Transformation-Flow-Value (TFV) theory (Koskela 2000). This is a theory that draws on the management literature and history as its base, and these origins are covered in Koskela (2000), where the roots of LC in production theory are explored. Koskela and his colleagues argue that:

\begin{abstract}
What is needed is a production theory and related tools that fully integrate the transformation, flow and value concepts. As a first step toward such integration we can conceptualise production simultaneously from these three points of view ... however, the ultimate goal should be to create a unified conception of production instead. (Koskela et. al. 2002: 214).
\end{abstract}

The TFV theory combines three points of view and is built on the insight that there are 'three fundamental phenomena in production that should be managed simultaneously'. The ideas of LC started with site operations but have been progressively applied to the supply chain, design and cost management and project delivery. These elements are brought together in the LPDS. The LPDS is detailed by Koskela et. al. (2002), and the LC tools and techniques by Ballard et. al. (2002). 
For the construction industry, the ideas and methods of LC in particular offer an alternative to management theories. There are three reasons, apart from the usefulness of conceptualising production processes in a discipline traditionally preoccupied with practical matters. First, LC was, prior to Radosavljevic and Bennett, the only theory of production to have been developed specifically for the construction industry, as discussed above in this paper. Therefore it provides insights into the range of processes that are involved, based on theory, that lead to propositions that can be tested by application to building and construction projects. The many case studies that have been published at the LC conferences over the years are all tests of the theory and practice of LC. These tests now add to a substantial body of evidence for the effectiveness of LC in a wide range of settings.

Second, the Lean Project Delivery System (LPDS, Ballard et. al. 2000) is an integrated approach to managing all the participants and stages of a project, from initiation to operation. Other approaches, such as value management, design management and indeed project management, only cover certain stages or a specific stage in the progress from conception to operation of a building, facility or structure. The LPDS is a framework starting from the project life-cycle, not adding bits on to achieve a comprehensive looking project plan.

Thirdly, drawing on LC theory and the LPDS as an application of that theory, the way building and construction projects are managed can be reconceptualised using the tools and techniques of lean construction. From the new management methods that LC engenders (for example, the activity definition model and set based design), efficiency and productivity gains that have proved to be so elusive under traditional project management in the construction industry might be realised.

These efficiency and productivity gains are also what Radosavljevic and Bennett are seeking. Their book puts forward a coherent model of CM and contains an abundance of propositions (25) that are intended as guidance in decision making, that one assumes would also improve performance. It is notable that they present the Japanese construction industry as the most advanced in terms of their theory (in providing a total service), and that LC is founded on the Toyota production system and the development of lean production in Japan. Lean is all about management, as Womack, Jones and Roos (1990) keep reminding us, and is the manufacturing philosophy of the age (see Fujimoto 2000 and Florida and Kenney 2000 for the extent of this). While the underlying vision of LC is an industrialised process of delivering construction projects, what LC is focused on is managing processes to deliver better outcomes. Clearly there is some relationship between these theories of CM and LC.

\section{Application of Theory}

Radosavljevic and Bennett say in their book that it is "a textbook for students and a checklist and guide of best practice for construction managers", not a research report. How this can be true of a book that explicitly sets out to develop a theory of CM and "to propose a radical new basis for CM research" is deeply mysterious (these quotes from the Preface on page $x v i i)$ as they go on to look at theory and its potential consequences for industry and research respectively.

Radosavljevic and Discuss the implications of the theory of CM and the IDIs for clients, design companies and construction companies and strategies. There are separate sections for the different types of construction companies and specialist contractors. They describe:

\footnotetext{
...the practical implications of the theory of construction management for customers and construction companies. The most complete application of the theory which is also the approach that delivers the highest levels of efficiency is a total construction service ... other approaches should be regarded as significant steps towards the greater efficiency provided by a total construction service (p. 229).
}

de Valence G (2012) 'A theory of construction management?', Australasian Journal of Construction Economics and Building, 12 (3) 95-100 
This view might not find total industry agreement, many firms are quite comfortable with current industry practices. To argue that "it is understandable to want to use a familiar approach but it ... is worth considering alternatives" (p. 229) rather glosses over the many issues associated with custom and practice that are deeply embedded in the construction industry. The propositions that underpin the theory are also used here to provide "guidance" for decision-making. How practitioners might react to these ideas, and whether and how they are put to use are interesting questions.

Chapter eleven of their book should get some serious attention from CM researchers. Here the authors start with the declaration that traditional project-based CM research be replaced by a "map of every possible construction project based on the reality of CM". What this actually means is using their key concepts of the number of teams, the quality of their relationships, the complexity and agreed objectives of the project to organize data. This seems an important idea - that CM research has a system of organizing and managing data so comparisons can be made across projects on some other basis than size, type, function and so on. Whether this could or should be done following Radosavljevic and Bennett's proposals for research is an open question.

However, there are two different aspects to this. Firstly, their model of construction management sets up a clear research path that should be followed up, and they admit:

Research data is required which measures each of the key concepts in the theory. Related to the map of every possible construction project, this data for many different projects provides the material needed to test the 25 propositions (p. 267).

Secondly, many of these construction management propositions can be developed into research projects in their own right, and indeed many already have a history of previous publications. For example, team organisation, interaction and communication are all topics in their own right. What Radosavljevic and Bennett have done, therefore, is to create a framework that a lot of existing CM research can be fitted into, and they have provided greater clarity of context and applicability than hitherto available, and they encourage further research into these topics. That in itself is important, because a few general organizing principles would be very useful in $\mathrm{CM}$.

A related point is the data set they envisage could be gathered and put through the model for the five different methods of project delivery. This is not one of the author's suggestions, because they see these strategies as a choice companies make, rather than as one of the criteria for organizing data. However, using CM strategies with the key concepts seems a logical step to make, and would be a link between traditional CM and their theory.

\section{Conclusion}

The upshot of all this is that the theory may turn out to be a significant step forward for CM research, rather than an end point. This is not a criticism, because this is exactly how the development of theories and advancement of knowledge proceeds. The authors have laid out a research agenda and invites testing and further research on their indicators. The claim is that this "would give the CM research community a robust basis for designing and undertaking future research". There are good reasons for the authors' confidence that this would advance CM, and equally good reasons to think that there will be a diversity of views on how this could or should be done. This is a debate that would move beyond the well-worn and rather sterile paths of relevance to industry, most appropriate methodology and project typologies.

The example research questions Radosavljevic and Bennett pose are on the elements of the theory: teams, the quality of relationships, performance variability, external interference and agreed objectives, followed by suggestions on research into the IDIs. Because the IDI values

de Valence G (2012) 'A theory of construction management?', Australasian Journal of Construction Economics and Building, 12 (3) 95-100 
are presented as the basis of strategic decisions on the appropriate CM strategy it would seem that this is the most important area for development.

Given the state of contemporary CM research this is a discussion we need, although not everyone will be convinced by Radosavljevic and Bennett method and conclusions. I found a lot to like in their argument, while reserving judgment on whether it is a theory or a collection of hypotheses. Many of the ideas are adventurous in a field where much of the literature is cautious, and in places it is ambitious in its view of how the industry could be rather than harking back to some idea of past glories. The overall framework it suggests for organizing $\mathrm{CM}$ research with its propositions and delivery strategies is an important and original contribution. There are many statements, declarations, descriptions and indeed propositions that will not get universal agreement but it makes many good points, it has a refreshingly different perspective on both past and future CM research, and it is open to discussion and debate. As any theory should be.

\section{References}

Ballard, G., Tommelein, I., Koskela, L. and Howell, G. (2002) 'Lean construction tools and techniques', in Best, R. and de Valence, G. (eds.) Building in Value: Design and Construction, Oxford, Butterworth-Heinemann, 227-255

de Valence, G. (2011) 'Theory and Construction Economics', in Modern Construction Economics, de Valence, G. (Ed.). London, Taylor and Francis, 1-13

Florida, R. and Kenney, M. (2000) 'Transfer and replication of organizational capabilities: Japanese transplant organisations in the US', in Dosi, G., Nelson, R.R. and Winter, S.G. (eds.) The Nature and Dynamics of Organizational Capabilities, Oxford, Oxford University Press

Fujimoto, T. (2000) 'Evolution of manufacturing systems and ex post dynamic capabilities', in Dosi, G., Nelson, R.R. and Winter, S.G. (eds.) The Nature and Dynamics of Organizational Capabilities, Oxford, Oxford University Press

Koskela, L. (1992) 'Application of the new production philosophy to construction', Technical Report No. 72, Center for Integrated Facilities Engineering, Dept. of Civil Engineering, Stanford University, CA, September 1992

Koskela, L. (2000) An exploration towards a production theory and its application to construction, Espoo, VTT Building Technology. VTT Publication 408

Koskela, L., Howell, G., Ballard, G. and Tommelein, I. (2002) 'The foundations of lean construction', in Best, R. and de Valence, G. (eds.) Building in Value: Design and Construction, Oxford, Butterworth-Heinemann, 211-225

Koskela, L. (2008) 'Is a theory of the built environment needed?', Building Research and Information, 36 (3), 211-15

Porter, M.E., (1980) Competitive Strategy: Techniques for analysing industries and competitors, New York, Free Press

Radosavljevic, M. and Bennett, J. (2012) Construction Management Strategies: A theory of construction management, Oxford, Wiley-Blackwell, 2012

Womack, J.P., Jones, D.T. and Roos, D. (1990) The machine that changed the world: Based on the Massachusetts Institute of Technology 5-million dollar 5-year study on the Future of the Automobile, Rawson Associates, Toronto, Collier Macmillan 